\title{
High-pressure carbon dioxide pneumoperitoneum induces oxidative stress and mitochondria-associated apoptotic pathway in rabbit kidneys with severe hydronephrosis
}

\author{
SHENG ZHAO ${ }^{1 *}$, WEI LI ${ }^{2 *}$, FAN CHENG $^{1}$, TING RAO ${ }^{1}$, WEIMIN YU ${ }^{1}$, \\ YUAN RUAN $^{1}$, RUN YUAN $^{1}$, XIAOBING YAO $^{1}$ and JINZHUO NING ${ }^{1}$ \\ Departments of ${ }^{1}$ Urology and ${ }^{2}$ Anesthesiology, Renmin Hospital of Wuhan University, \\ Wuhan, Hubei 430000, P.R. China
}

Received May 30, 2018; Accepted October 11, 2018

DOI: $10.3892 / \mathrm{ijmm} .2018 .3986$

\begin{abstract}
The primary aim of the present study was to investigate the potential effect of high-pressure carbon dioxide $\left(\mathrm{CO}_{2}\right)$ pneumoperitoneum on kidneys with severe hydronephrosis and to investigate the possible underlying mechanism. A total of 18 rabbits underwent a surgical procedure inducing severe hydronephrosis. Rabbits were then divided at random into three groups $(\mathrm{n}=6$ each) and subjected to intraabdominal pressure of 0,8 or $18 \mathrm{mmHg}$, respectively. $\mathrm{CO}_{2}$ inflation lasted for $90 \mathrm{~min}$ in the pneumoperitoneum groups. Oxidative stress was assessed by measurements of reactive oxygen species (ROS). Activation of apoptosis was analyzed by western blot analysis of B-cell lymphoma 2 (Bcl-2), Bcl-2-associated $\mathrm{x}$ protein (Bax), cytochrome c (Cyt c), caspase-3 and caspase-9 levels. In addition, TUNEL assay, hematoxylin and eosin (H\&E) staining, measurement of mitochondrial membrane potential (MMP) and detection of changes to kidney ultramicrostructure were performed. In the 0 and $8 \mathrm{mmHg}$ groups, all results were normal and similar. However, in the $18 \mathrm{mmHg}$ group, the kidneys suffered oxidative damage and mitochondrial injuries, and increased ROS levels, lower MMP and mitochondrial vacuolization were observed. Furthermore, the mitochondrial/caspase-dependent pathway of apoptosis was activated, as indicated by the apoptotic index, and the expression levels and translocation of Bax, Bcl-2, Cyt c, caspase-3 and caspase-9. Therefore, it is concluded that high-pressure $\mathrm{CO}_{2}$ pneumoperitoneum induces oxidative damage and
\end{abstract}

Correspondence to: Dr Fan Cheng, Department of Urology, Renmin Hospital of Wuhan University, 99 Zhang Zhidong Road, Wuchang, Wuhan, Hubei 430000, P.R. China

E-mail: urology1969@aliyun.com

${ }^{*}$ Contributed equally

Key words: oxidative stress, mitochondria, apoptosis, kidney hydronephrosis, high-pressure carbon dioxide pneumoperitoneum apoptosis in rabbit kidneys with severe hydronephrosis, which is associated with the mitochondrial apoptotic pathway.

\section{Introduction}

Minimally invasive surgery using gas-induced pneumoperitoneum has become an important surgical approach. The reduced pain, shorter postoperative hospital stay and better cosmetic results also make this technique attractive for patients (1-3). Carbon dioxide $\left(\mathrm{CO}_{2}\right)$ is the most commonly used gas for insufflation of the abdominal cavity to provide better exposure during laparoscopic surgery (4). However, an increasing numbers of studies have reported that several physiological complications are closely associated with high intraabdominal pressure caused by $\mathrm{CO}_{2}$ (5-7).

Kidneys, as important splanchnic organs, are inevitably affected by intraabdominal pressure $(8,9)$. Previous clinical and experimental studies have demonstrated that the laparoscopic procedure with pneumoperitoneum provides a typical model of ischemia/reperfusion (I/R) injury in the organs (10). Previous animal experiments have demonstrated that high and erratic elevations of intraabdominal pressure can decrease venous return, compress the renal vasculature and cause systemic hormonal changes, which eventually significantly decrease renal blood flow, urinary output and glomerular filtration rate (11). Further studies have observed increases in renal ischemia and oxidative stress response in the presence of increased intraabdominal pressure $(12,13)$. Although abdominal deflation at the end of laparoscopic procedures reduces the intraabdominal pressure and increases renal perfusion, damage from the ischemic injury remains. Nevertheless, the majority of studies associated with pneumoperitoneum pressure damage involve normal kidneys (14); however, a number of patients who undergo laparoscopic surgery also exhibit a degree of kidney obstruction. To date, only a limited number of studies have reported how pneumoperitoneum affects kidneys with hydronephrosis (15).

In our previous study, the effect of pneumoperitoneum pressure on rabbit kidneys with no hydronephrosis, and with mild or severe hydronephrosis was investigated (16). The results indicated that severely obstructed kidneys have reduced cell 
tolerance to intraabdominal pressure, and that they are more likely to suffer oxidative damage and mitochondrial injuries when they were exposed to pneumoperitoneal pressure. It is generally accepted that oxidative damage and mitochondrial injuries are common ischemic pathological changes that can eventually cause apoptosis (17). Considering these facts, it can be speculated that with the increase of pneumoperitoneal pressure, apoptosis may occur as a consequence of severe oxidative damage and mitochondrial injuries in rabbit kidneys with severe hydronephrosis. Therefore, the present study aimed to examine the effects of high-pressure pneumoperitoneum with $\mathrm{CO}_{2}$ on the kidneys of rabbits with severe hydronephrosis and to investigate the possible mechanism involved.

\section{Materials and methods}

Animals and groups. In total, 18 adolescent male New Zealand rabbits were purchased from the Wuhan Institute of Biotechnology (Wuhan, China). The average weight of the rabbits was $2.2 \pm 0.3 \mathrm{~kg}$, and the average age was $6 \pm 0.2$ months All experiments were performed according to the guidelines for the Care and Use of Laboratory Animals (18) and were approved by the Ethics and Research Committee of the Wuhan University Medical School (Wuhan, China). The rabbits were housed in standard cages with free access to tap water and food in a room with a temperature of $18-25^{\circ} \mathrm{C}$ and relative humidity of $45-55 \%$. The room was kept quiet to avoid any stress-inducing factors during the experimental period. All animals were determined to be healthy on the basis of clinical examinations, and were allowed to feed and drink freely 1 week before the experiment to adapt to environmental conditions.

The rabbits were randomly divided into three groups consisting of 6 rabbits each, including the 0,8 and $18 \mathrm{mmHg}$ groups. All these rabbits underwent surgical procedures to induce severe hydronephrosis. Following the surgery, the abdomens of the rabbits in these groups were insufflated with $\mathrm{CO}_{2}$ to maintain an intraabdominal pressure of 0,8 or $18 \mathrm{mmHg}$, respectively.

Experimental protocol. Following the method described by Wen et al (19), all the rabbits underwent surgery to establish a model of kidneys with hydronephrosis. Briefly, the rabbits were initially anesthetized by auricular vein injection of sodium pentobarbital at a dose of $30 \mathrm{mg} / \mathrm{kg}$ at room temperature. After $10 \mathrm{~min}$, the left ureter and psoas muscle were exposed through a midline abdominal incision, and the proximal ureter was buried in a $2-\mathrm{cm}$ notch within the psoas muscle. After 2 weeks, B-ultrasonography was used to confirm hydronephrosis. Pyelic distention levels of $1.69 \pm 0.34 \mathrm{~cm}$ and parenchymal thickness of $0.22 \pm 0.05 \mathrm{~cm}$ were observed. Next, the rabbits were randomly assigned to three groups, including the 0,8 and $18 \mathrm{mmHg}$ groups, and a second laparotomy was then performed. Following anesthetization, a Veress needle was introduced in the abdomen, and the incision was sutured to prevent $\mathrm{CO}_{2}$ leakage from the abdomen. Intra-abdominal pressure was induced with an insufflator (Stryker, Kalamazoo, MI, USA) that delivered filtered medical $\mathrm{CO}_{2}$ at body temperature with a flow rate of $0.51 / \mathrm{min}$. The three groups of rabbits were subjected to intraabdominal pressures of 0,8 or $18 \mathrm{mmHg}$, respectively, for $90 \mathrm{~min}$. Subsequent to the insufflation, the pneumoperitoneum was released, the psoas muscle obstruction was relieved, and the abdomen was sutured. The rabbits were sacrificed 2 days after the pneumoperitoneum with $150 \mathrm{mg} / \mathrm{kg}$ sodium pentobarbital $(20 \%)$ through ear marginal vein injection, and the left kidneys were collected for biochemical and histological evaluations.

Tissue processing. Following sacrifice, the abdominal area of the rabbits was fully exposed, and the experimental kidneys were removed carefully with sharp scissors. The kidneys were then placed into cold $0.9 \%$ saline solution to wash away most of the blood. Next, the renal capsule and the adipose tissues around the kidney were carefully removed with tweezers, avoiding oppression of the renal tissue during the entire process. Finally, the unwanted renal pelvis was carefully removed with small scissors, appropriate sections of renal tissue were cut off with a sharp blade, and the renal tissue was washed with cold $0.9 \%$ saline solution for three times to clear the residual blood. The tissue samples were treated differently according to different detection methods.

Detection of reactive oxygen species (ROS). All of the rabbits were sacrificed 2 days after pneumoperitoneum. Kidneys were carefully removed and washed with cold $0.9 \%$ saline solution three times. The kidney tissue samples were homogenized (T25; IKA-Werke GmbH \& Co. KG, Staufen, Germany) in $100 \mathrm{mmol} / \mathrm{l}$ phosphate buffer and centrifuged at $13,000 \mathrm{x}$ g for $15 \mathrm{~min}$ at $4^{\circ} \mathrm{C}$ (Heraeus Biofuge Primo R; Thermo Fisher Scientific, Inc., Waltham, MA, USA), following which the supernatants were collected. The bicinchoninic acid method was used to detect protein concentration. Then the homogenized supernatants were incubated with $1 \mathrm{mmol} / \mathrm{l}$ 2,7-dichlorodihydrofluorescein diacetate (Nanjing Jiancheng Bioengineering Institute, Nanjing, China) for $30 \mathrm{~min}$ at $37^{\circ} \mathrm{C}$. Subsequently, an automatic microplate reader (Multiskan MK3; Thermo Fisher Scientific, Inc.) was used to detect the absorbance at $500 \mathrm{~nm}$. The results are expressed as the arbitrary units per $\mathrm{mg}$ of protein.

Measurement of mitochondrial membrane potential (MMP). An MMP detection kit (Beyotime Institute of Biotechnology, Haimen, China) was used to determine changes in MMP, according to the manufacturer's protocol. Briefly, renal tissue was cleaned with $0.9 \%$ normal saline and digested in a trypsin solution (Beyotime Institute of Biotechnology) at $37^{\circ} \mathrm{C}$ for $\sim 20 \mathrm{~min}$, and the reaction was terminated by addition of $30 \%$ fetal bovine serum (Hangzhou Sijiqing Biological Engineering Materials Co., Ltd., Hangzhou, China). Suspended cells were centrifuged at 2,000 x $\mathrm{g}$ for $4 \mathrm{~min}$ at $4^{\circ} \mathrm{C}$ and then washed three times with PBS. Subsequent to this step, JC-1 was added at a final concentration of $0.01 \mathrm{M}$. Following incubation for $30 \mathrm{~min}$ at $37^{\circ} \mathrm{C}$, the cells (approximately $3 \times 10^{5}$ cells $/ \mathrm{ml}$ ) were washed three times with wash buffer and immediately analyzed by flow cytometry (FACSCalibur; BD Biosciences, Franklin Lakes, NJ, USA) and Flowjo software (version 7.6.1, BD Biosciences).

Hematoxylin and eosin (H\&E) staining, and TUNEL detection. Rabbit kidney tissues in all three groups were 
harvested and fixed in 10\% formalin ( $\mathrm{pH} 7.0)$ for a time period not exceeding $24 \mathrm{~h}$. The tissues were processed routinely for paraffin embedding, and 5- $\mu \mathrm{m}$ paraffin-embedded sections were cut for detection. The tissue sections were deparaffinized using xylene and rehydrated using a graded ethanol series prior to staining with H\&E. In order to compare the kidney injury and renal cell apoptosis in these three groups, sections were screened per high-power field (HPF) under a microscope (Nikon 80i; Nikon Corporation, Tokyo, Japan). On each slide, 10 HPFs in the cortex and outer medulla were randomly selected, and 100 cells were randomly counted in each of these fields. Kidney injury was graded on the basis of H\&E staining, as follows: 0 , absence of necrosis; 1 , mild necrosis; 3 , moderate necrosis; and 5 , severe necrosis.

Apoptotic scores were also determined with TUNEL staining using the In Situ Apoptosis Detection kit (Roche Applied Sciences, Basel, Switzerland). Apoptotic nuclei were stained brown, while negative nuclei were stained blue. The apoptotic index was calculated based on the percentage of positive nuclei. All quantifications were performed by two pathologists in a blinded manner.

Kidney ultramicrostructure examination by electron microscopy. Renal cortex tissues from the three groups were fixed for $24 \mathrm{~h}$ in $2.5 \%$ paraformaldehyde at $4^{\circ} \mathrm{C}$ and subsequently fixed at $4^{\circ} \mathrm{C}$ for $2 \mathrm{~h}$ with $2 \%$ osmium tetroxide. The kidney samples were then washed with PBS twice, dehydrated with a series of ethanol solutions and embedded in Spurr epoxy resin at $45^{\circ} \mathrm{C}$ for $12 \mathrm{~h}$. Next, tissue specimens were cut into $50 \mathrm{~nm}$ sections on an ultra-microtome using diamond knives, followed by washing and staining with $2 \%$ aqueous uranyl acetate at $25^{\circ} \mathrm{C}$ for $\sim 1 \mathrm{~h}$. Finally, a minimum of 10 random fields of view from each section were visualized under a transmission electron microscope (H-600; Hitachi, Ltd., Tokyo, Japan).

Western blot analysis. To determine the possible mechanisms underlying the apoptosis induced by pneumoperitoneum, the expression levels of B-cell lymphoma 2 (Bcl-2), Bcl-2-associated x protein (Bax), cytochrome c (Cyt c), caspase-3 and caspase- 9 were detected in rabbit kidney tissues using western blot analysis. Briefly, 6 rabbits from each group were rapidly sacrificed 2 days after pneumoperitoneum, and the kidneys were removed. Next, tissues were washed three times with PBS (pH 7.2) and homogenized using an Ultra-Turrax (T25; IKA-Werke $\mathrm{GmbH} \& \mathrm{Co} . \mathrm{kg}$ ) in radioimmunoprecipitation assay buffer (Beyotime Institute of Biotechnology) containing phenylmethylsulfonyl fluoride (Beyotime Institute of Biotechnology). The samples were then centrifuged at $14,000 \mathrm{x} \mathrm{g}$ for $20 \mathrm{~min}$ at $4^{\circ} \mathrm{C}$. For Cyt $\mathrm{c}$ testing, the cytosolic and mitochondrial extracts were obtained by the mitochondrial extraction kit (Beyotime Institute of Biotechnology) following the manufacturer's protocol. In addition, COX-IV and $\beta$-tubulin were used as controls for the detection of Cyt $\mathrm{c}$ in the mitochondria and cytoplasm, respectively. The concentration of the protein was detected using the bicinchoninic acid method. Proteins in each group were subjected to $12 \%$ or $15 \%$ sodium dodecyl sulfate-polyacrylamide gel electrophoresis and transferred onto a polyvinylidene difluoride membrane for $1-2 \mathrm{~h}$ at $200 \mathrm{~mA}$, according to their molecular weight. For each group, $\sim 40 \mu \mathrm{g}$ proteins were added onto the gels per

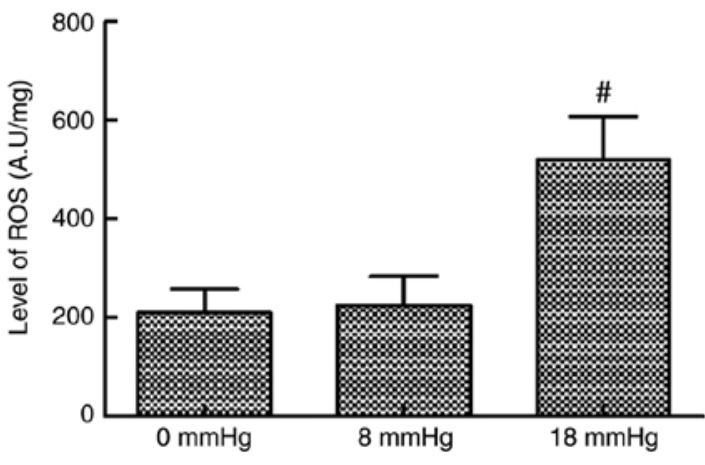

Figure 1. Levels of ROS in severely hydronephrotic rabbit kidneys perfused at different pneumoperitoneum pressures. ${ }^{\#} \mathrm{P}<0.05$ vs. the $0 \mathrm{mmHg}$ group. ROS, reactive oxygen species.

lane for detection. Subsequent to blocking with Tris-buffered saline/Tween-20 containing 5\% dried skim milk for $1 \mathrm{~h}$ at room temperature (approximately $25^{\circ} \mathrm{C}$ ), the membranes were incubated with primary antibodies overnight at $4^{\circ} \mathrm{C}$. The antibodies used for western blot analyses were as follows: Bax (PA5-70418; 1:3,000; Thermo Fisher Scientific, Inc.), Bcl-2 (PA5-68611; 1:2,000; Thermo Fisher Scientific, Inc.), Cyt c (NB100-56503; 1:5,000; Novus Biologicals, LLC, Littleton, CO, USA), caspase-3 (ab90437; 1:1,000; Abcam, Cambridge, UK), caspase-9 (ab115161; 1:3,000; Abcam), $\beta$-actin (ab28052; 1:5,000; Abcam), Cyt c oxidase (COX)-IV (ab66739; 1:5,000; Abcam) and $\beta$-tubulin (ab56676; 1:4,000; Abcam). Proteins were subsequently incubated for $1 \mathrm{~h}$ at room temperature with anti-mouse/rabbit secondary antibody (P/N 925-32210 or P/N 925-32211; 1:10,000; LI-COR Biosciences, Lincoln, NE, USA), which was conjugated to IRDye $800 \mathrm{CW}$. Finally, the fluorescence signal emitted by the secondary antibody was quantified by a western blot detection system (Odyssey Infrared Imaging; LI-COR Biosciences), and semi-quantitative analysis was conducted to determine the corresponding protein expression levels (Image Studio version 5.2.5; LI-COR Biosciences).

Statistical analysis. All data are presented as the means \pm standard deviations, and all analyses were performed in duplicate. One-way analysis of variance and Turkey's test were performed for statistical comparison using IBM SPSS software, version 19 (IBM Corp., Armonk, NY, USA). P-values that were $<0.05$ were considered to denote statistically significant differences.

\section{Results}

ROS levels. The ROS levels in kidney tissues were comparable between the 0 and $8 \mathrm{mmHg}$ groups. However, when the intraabdominal pressure reached $18 \mathrm{mmHg}$, the ROS level significantly increased compared with the 0 and $8 \mathrm{mmHg}$ groups (Fig. 1).

Changes in MMP levels. Disruption of MMP is one of the earliest events in apoptosis (20). JC-1, as a fluorescent probe, mainly exists in the mitochondrial matrix as a polymer, which can emit red fluorescence when MMP levels are high. However, when the MMP levels are low, JC-1 mainly exists 

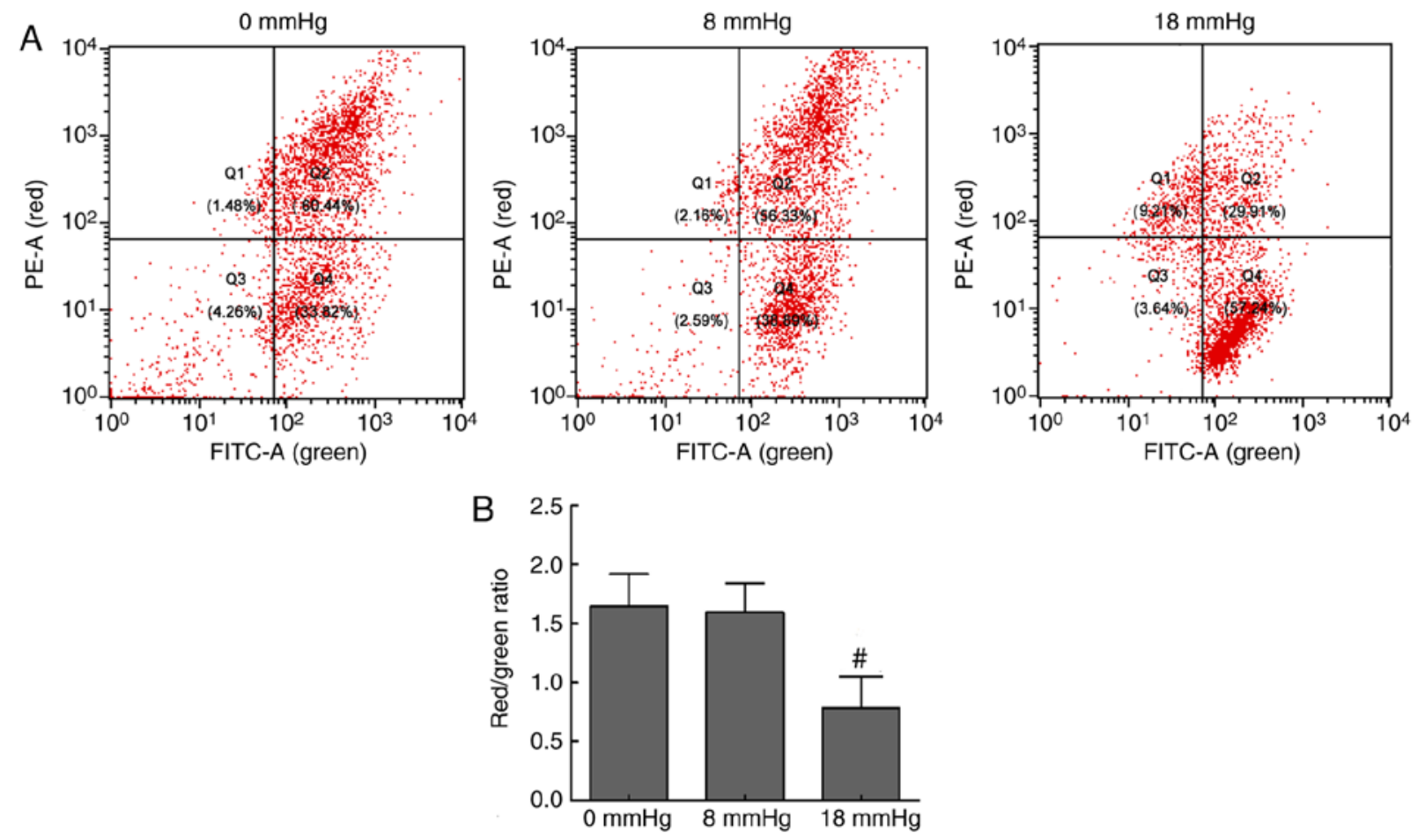

Figure 2. MMP of renal cells subjected to different pneumoperitoneum pressures in rabbit kidneys with severe hydronephrosis. (A) Flow cytometric analysis of MMP changes. PE-A represents the red fluorescence, while FITC-A represents the green fluorescence. MMP levels are expressed as the ratio of red to green fluorescence intensity, indicated in Q2 and Q4. (B) Ratio of red to green fluorescence intensity of renal cells in rabbits with severe hydronephrosis under different intraabdominal pressures. ${ }^{\#} \mathrm{P}<0.05$ vs. the 0 and $8 \mathrm{mmHg}$ groups. MMP, mitochondrial membrane potential.
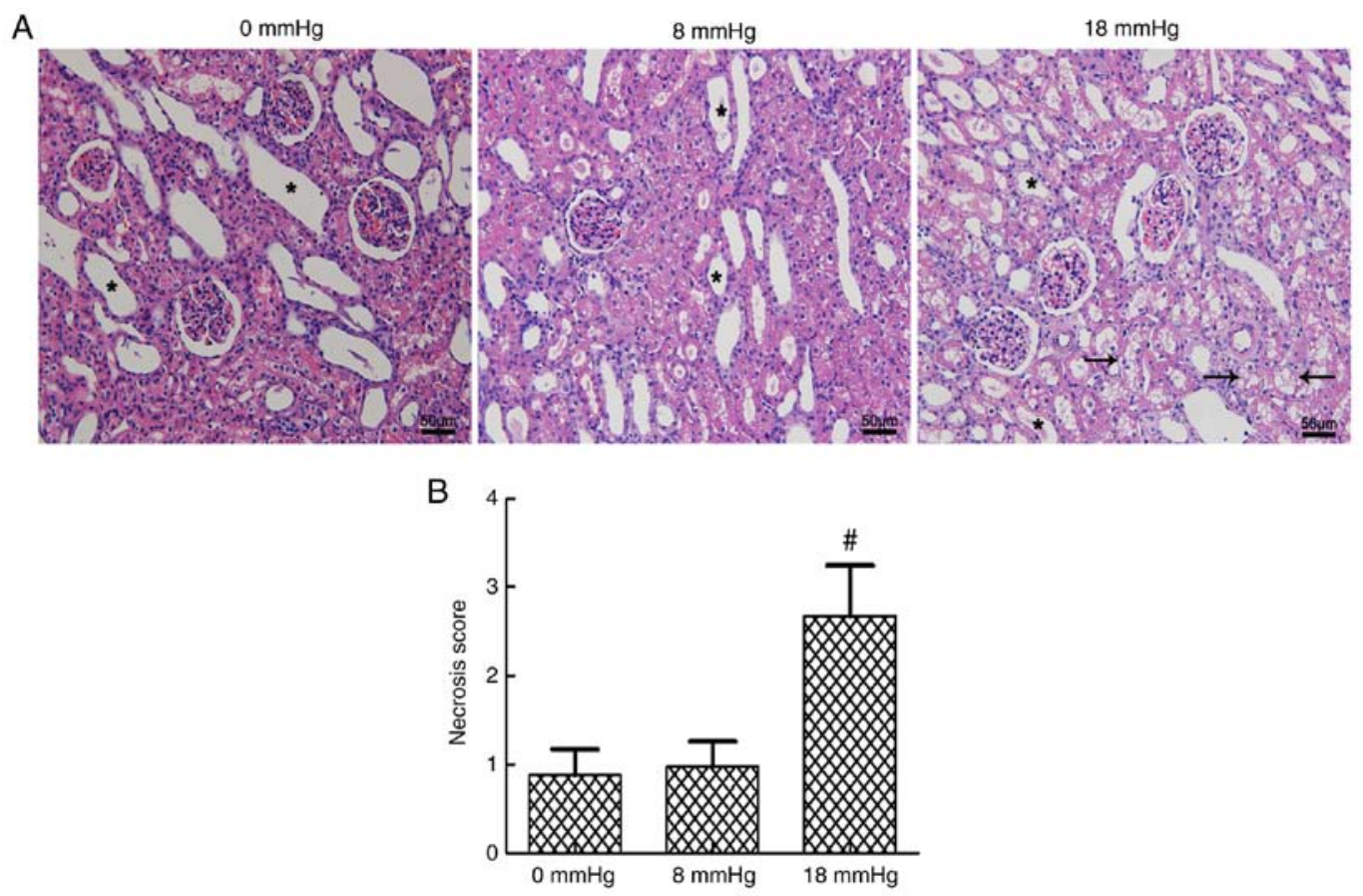

Figure 3. Histological evaluation of rabbit kidneys with severe hydronephrosis subjected to different pneumoperitoneum pressures. (A) Hematoxylin and eosin staining images of kidney sections (magnification, x200). Asterisks indicate examples of expansive kidney tubules caused by severe hydronephrosis, while the arrows display examples of necrotic tubular cells. (B) Tubular necrosis scores in each group. ${ }^{*} \mathrm{P}<0.05$ vs. the 0 and $8 \mathrm{mmHg}$ groups.

in the cytoplasm as monomers, which can emit green fluorescence. Thus, a decrease in the red/green fluorescence intensity ratio indicates MMP loss (21). In the present study, the flow cytometry scatter plots and the red/green ratios were obtained, and are shown in Fig. 2. The renal cells exhibited strong red fluorescence and relatively weak green fluorescence in the 0 and $8 \mathrm{mmHg}$ groups. However, when the pneumoperitoneum pressure was increased to $18 \mathrm{mmHg}$, the red fluorescence was 
A

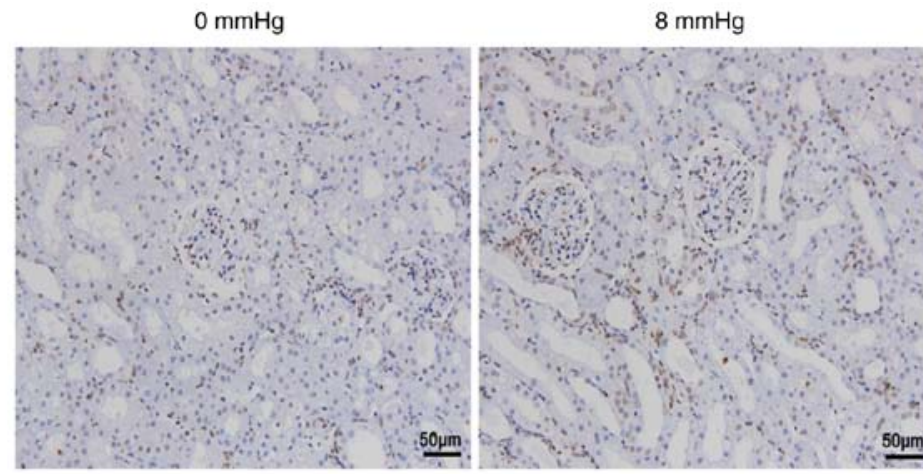

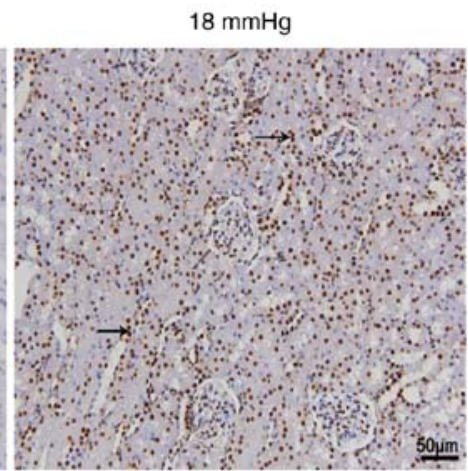

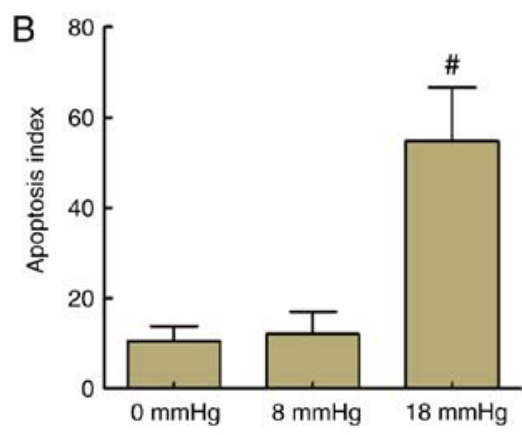

Figure 4. TUNEL detection of rabbit kidneys with severe hydronephrosis subjected to different pneumoperitoneum pressures. (A) TUNEL analysis images of kidney sections (magnification, x200). The arrows in the figure indicate examples of TUNEL-positive cells. (B) Apoptosis index of renal cells in each group. ${ }^{\#} \mathrm{P}<0.05$ vs. the 0 and $8 \mathrm{mmHg}$ groups.

attenuated and green fluorescence was enhanced, which indicated a loss of MMP levels (Fig. 2). These changes suggested mitochondrial damage and early cell apoptosis associated with the mitochondrial pathway in the $18 \mathrm{mmHg}$ group.

Kidney necrosis. Certain degrees of expansive kidney tubules were observed in all three groups due to the establishment of rabbit kidney models with severe hydronephrosis. The tubular necrosis scores were at a relatively low level when the intraabdominal pressure was only 0 or $8 \mathrm{mmHg}$, and no significant difference was observed between these two groups. However, a sudden significant increase in the tubular necrosis score was detected when the pneumoperitoneum pressure reached $18 \mathrm{mmHg}$ (Fig. 3).

Kidney apoptosis. In the 0 and $8 \mathrm{mmHg}$ groups, only a few nuclei were stained brown, and no significant difference was observed between these two groups. By contrast, $>50 \%$ of the nuclei were stained brown in the $18 \mathrm{mmHg}$ group, which indicated that the total number of apoptotic cells was markedly increased. These results indicated that apoptosis occurred in the kidneys of rabbits with severe hydronephrosis in the presence of increased pneumoperitoneum pressure (Fig. 4).

Ultramicrostructure changes of tubular cells. Mitochondrialdependent apoptosis is one of the key apoptosis mechanisms (22). This mechanism involves ultramicrostructure changes in the cells. In the current study, transmission electron microscopy was performed to detect the apoptosis in renal cells by investigating changes to the mitochondria. In the $0 \mathrm{mmHg}$ group, cells had an overall normal appearance, with few swollen or vacuolar mitochondria observed. In the $8 \mathrm{mmHg}$ group, similar results were observed. However, in the $18 \mathrm{mmHg}$ group, the majority of the mitochondria were swollen and vacuolar (Fig. 5). These findings revealed that the mitochondria-mediated pathway was involved in apoptosis induced by high-pressure pneumoperitoneum in obstructed rabbit kidneys.

Expression levels of Bax and Bcl-2. An increase in the expression of the pro-apoptotic protein Bax and reduced expression of the anti-apoptotic protein Bcl-2 are considered important changes in early apoptosis (23). The results of the present study demonstrated that the expression of Bax was significantly increased and the expression of Bcl-2 was markedly decreased when the pneumoperitoneum pressure reached $18 \mathrm{mmHg}$. Notably, no significant changes were observed between the 0 and $8 \mathrm{mmHg}$ groups (Fig. 6).

Release of Cyt c. Cyt $\mathrm{c}$ is an intermembrane space protein that is tightly associated with cardiolipin, a key lipid component of the inner mitochondrial membrane. The release of Cyt $\mathrm{c}$ from mitochondria to the cytosol is considered one of the key steps in the mitochondria-associated apoptosis (24). In the current study, the expression of Cyt $\mathrm{c}$ in mitochondria and cytosol were separately detected (Fig. 7). The results revealed that the majority of Cyt $\mathrm{c}$ existed in the mitochondria rather than the cytosol in the 0 and $8 \mathrm{mmHg}$ groups, indicating that only limited amount of Cyt c was released. No significant difference was observed between these two groups. However, in the $18 \mathrm{mmHg}$ group, the majority of the Cyt c existed in the cytosol rather than the mitochondria, indicating that rabbit kidneys with hydronephrosis subjected to $18 \mathrm{mmHg}$ 
A

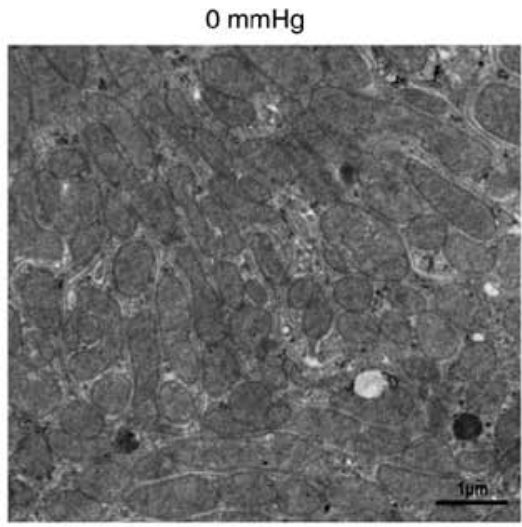

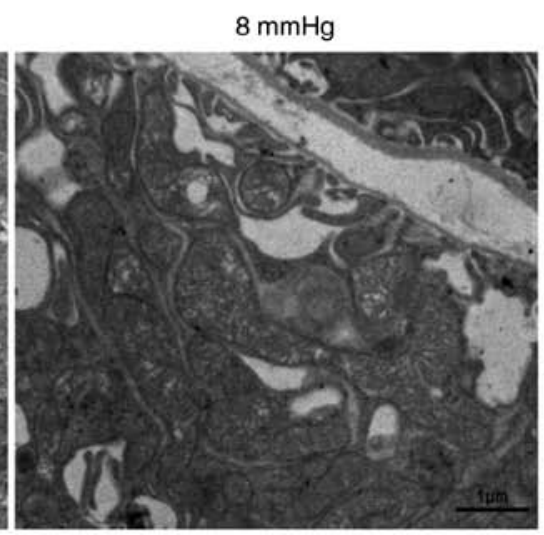

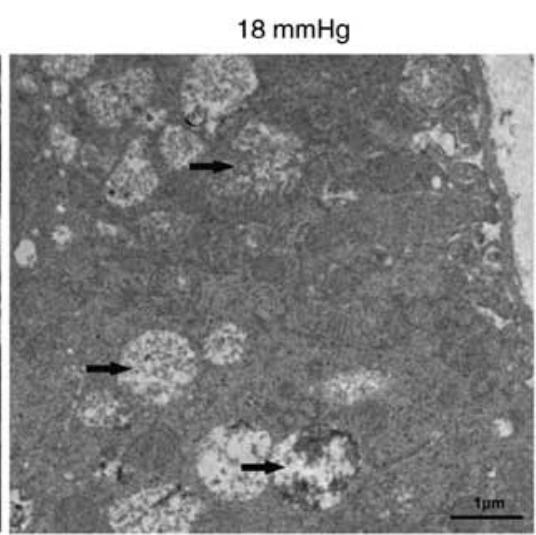

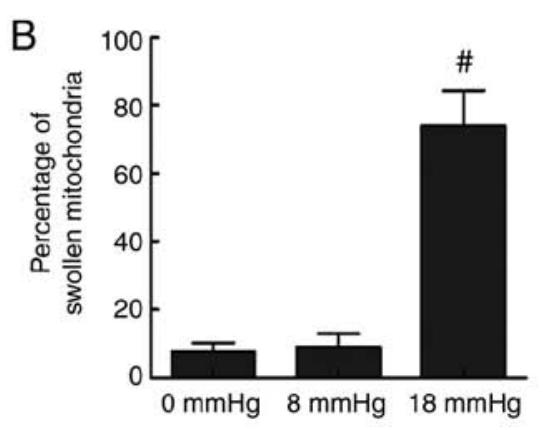

Figure 5. Ultramicrostructural changes of rabbit kidneys with severe hydronephrosis subjected to different pneumoperitoneum pressures. (A) Transmission electron microscopy images of ultramicrostructural changes in different groups (magnification, x3,000). The arrows indicate examples of swollen and vacuolar mitochondria. (B) Percentage of swollen mitochondria in each group, indicating apoptotic changes. ${ }^{\#} \mathrm{P}<0.05 \mathrm{vs}$. the 0 and $8 \mathrm{mmHg}$ groups.

pneumoperitoneum were characterized by Cyt $\mathrm{c}$ release from the mitochondria to the cytosol (Fig. 7).

Activity of caspase-3 and caspase-9. The release of Cyt c activates caspase-9, a cysteine protease, and later cleaved caspase- 9 activates caspase- 3 and forms cleaved caspase- 3 , which is responsible for cell apoptosis (25). The current study detected the activities of caspase- 3 and caspase- 9 to assess whether the caspase-dependent pathway was involved in rabbit kidneys with severe hydronephrosis subjected to pneumoperitoneum. As shown in Fig. 8, cleaved caspase-9 and cleaved caspase-3, as well as the expression ratio of cleaved-caspase-3/pro-caspase-3 or cleaved-caspase-9/pro-caspase-9, were significantly increased when the intraabdominal pressure reached $18 \mathrm{mmHg}$. However, no significant changes were observed between the 0 and $8 \mathrm{mmHg}$ groups (Fig. 8).

\section{Discussion}

Pneumoperitoneum, although generally considered to be essential for adequate exposure in laparoscopic surgery, has adverse effects on renal physiology (26). A large number of trials have revealed the side effects of pneumoperitoneum; however, these trials have mainly focused on renal blood flow changes and renal function $(27,28)$. A previous study revealed that the glomerular filtration rate decreased by 14 and $48 \%$ in rats when an intraabdominal pressure of 7 and $14 \mathrm{mmHg}$ was applied, respectively. In parallel, the renal plasma flow decreased by 28 and $57 \%$ under these conditions (29). Certain studies have emphasized that high intraabdominal pressure can noticeably decrease renal blood flow, while other studies reported that renal blood flow returned to the normal range following deflation (30,31). During the hypoperfusion and subsequent reperfusion periods, a typical $I / R$ injury may occur. Several studies in animals and humans have investigated I/R injury following laparoscopic surgeries (32-34). Pneumoperitoneum may cause an increase in the oxidative stress, and active oxygen species (ROS) may cause damage to lipids and proteins during oxidative stress. A previous study has also demonstrated that oxidative stress response decrease and antioxidant defense systems strengthened with the administration of dexmedetomidine prior to pneumoperitoneum (35). Furthermore, a typical I/R injury is closely associated with oxidative damage and mitochondrial injuries (36), which can eventually cause cell apoptosis or death.

As mentioned earlier, hydronephrosis is a common urological disease that can be caused by a kidney stone, tumor or congenital anomalies. Kidneys with hydronephrosis have a thinner renal cortex and subnormal blood perfusion, while the hydronephrosis itself has adverse effects on renal tubule function, causing hydronephrotic kidneys to be more likely to suffer hypoxia problems (37). Severe hydronephrosis leads to prolonged operating time in laparoscopic surgery, which may consequently lead to increased oxidative stress (38). Based on these facts and the observations of our previous study (16), it can be inferred that high-pressure $\mathrm{CO}_{2}$ pneumoperitoneum may cause severe oxidative stress, mitochondrial injuries and even cell apoptosis in rabbit kidneys with severe hydronephrosis. Therefore, the present study examined the effects of high-pressure $\mathrm{CO}_{2}$ pneumoperitoneum on kidneys with severe hydronephrosis and investigated the possible underlying mechanism. 

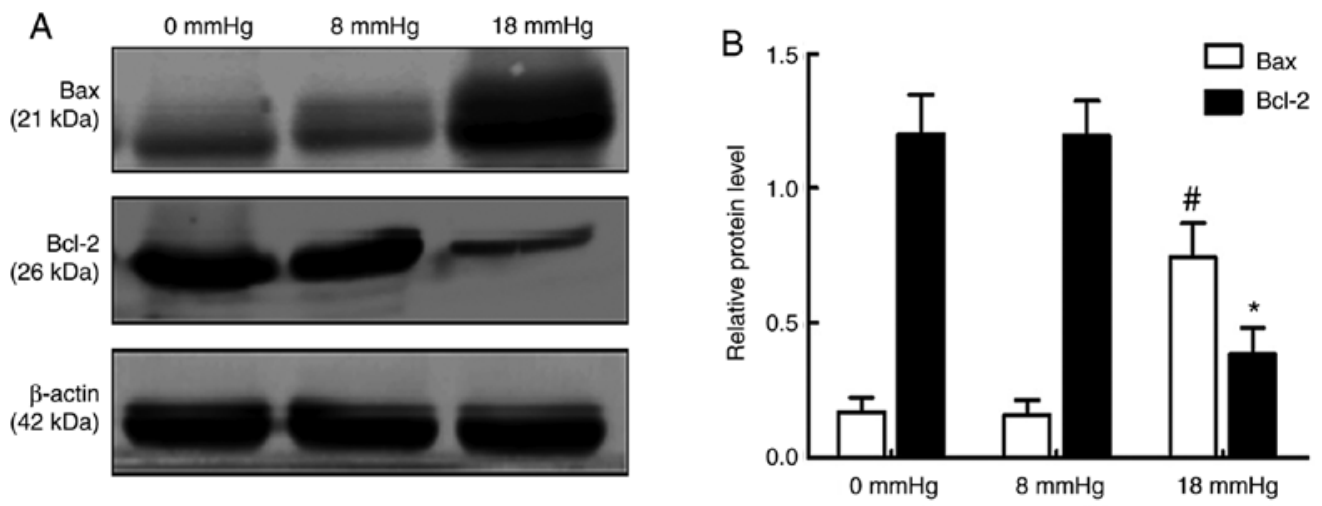

Figure 6. Expression levels of Bax and Bcl-2 in rabbit kidneys with severe hydronephrosis subjected to different pneumoperitoneum pressures. (A) Representative western blots and (B) relative protein expression levels of Bax, Bcl-2 and $\beta$-actin in rabbit kidneys from different groups. All data are expressed as the mean \pm standard deviation of three experiments, and each experiment included triplicate repeats. ${ }^{\#} \mathrm{P}<0.05$ vs. the 0 and $8 \mathrm{mmHg}$ groups. ${ }^{*} \mathrm{P}<0.05$ vs. the 0 and $8 \mathrm{mmHg}$ groups. Bcl-2, B-cell lymphoma 2; Bax, Bcl-2-associated x protein.

A

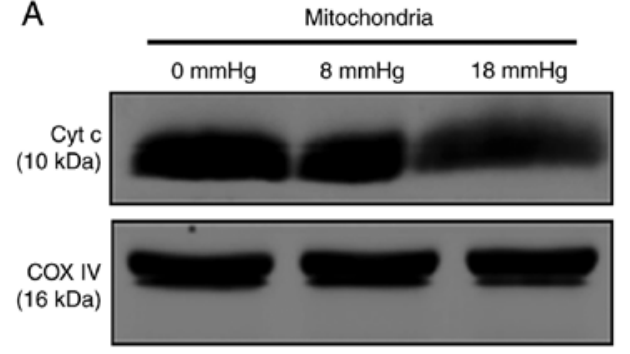

B

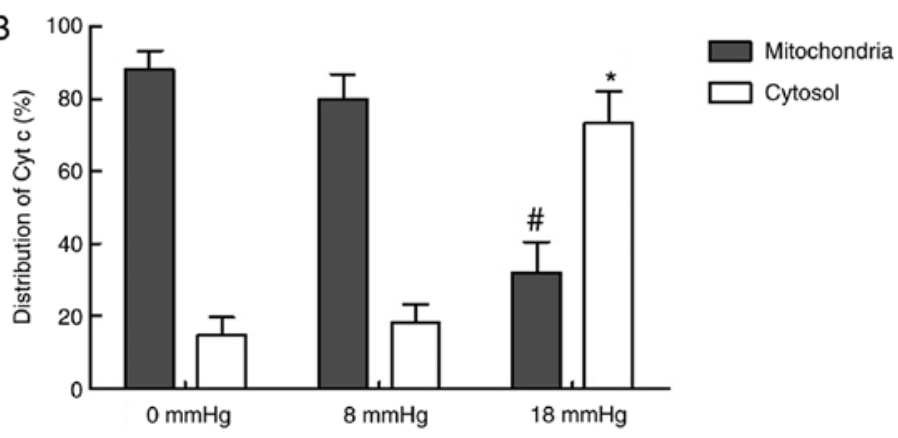

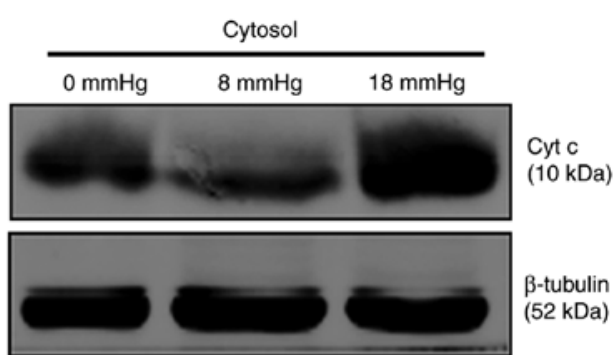

Figure 7. Expression of Cyt $\mathrm{c}$ in mitochondria and cytosol in rabbit kidneys with severe hydronephrosis subjected to different pneumoperitoneum pressures. (A) Representative western blots showing the protein expression levels of Cyt c, COX-IV and $\beta$-tubulin in mitochondria and cytosol in rabbit kidneys from different groups. (B) Distribution of Cyt $\mathrm{c}$ in mitochondria and cytosol in each group. All data are representative of three independent experiments. ${ }^{\sharp} \mathrm{P}<0.05$ vs. the 0 and $8 \mathrm{mmHg}$ groups. "P<0.05 vs. the 0 and $8 \mathrm{mmHg}$ group. Cyt c, cytochrome C; COX-IV, Cyt c oxidase-IV.

In I/R injury, the generation of ROS appears to be an important source of tissue damage. To a certain extent, ROS content represents the degree of oxidative damage $(39,40)$. In the experiments of the present study, the ROS levels, histological changes and apoptosis index were first detected to evaluate oxidative stress and tissue damage. As expected, higher oxidative stress, higher apoptosis index and more severe morphological changes were observed in the $18 \mathrm{mmHg}$ group as compared with the 0 and $8 \mathrm{mmHg}$ groups. Excessive ROS induces the peroxidation of mitochondrial membrane lipids, which promotes extensive release of ROS and spurs a vicious cycle, eventually leading to a loss of MMP $(41,42)$. Accordingly, the MMP was tested by JC-1 staining in the current study, and the results identified a significant decrease in MMP in the $18 \mathrm{mmHg}$ group. To confirm the changes to the mitochondria, the ultrastructure of kidneys was also observed by electron microscopy. As expected, large swollen and vacuolar mitochondria were detected in the $18 \mathrm{mmHg}$ group, while in the 0 and $8 \mathrm{mmHg}$ groups, few abnormal changes were observed. The significant reduction of MMP, mitochondrial injuries and apoptosis largely suggested a mitochondrially mediated phenomenon, which is associated with the collapse of transmembrane potential, resulting in the expulsion of apoptogenic molecules.

The mitochondrial pathway is characterized by the release of apoptosis-promoting factors, such as Cyt c and apoptosis-inducing factor (AIF), from the mitochondria (43). The release of Cyt $\mathrm{c}$ from mitochondria to cytosol can activate the initiator caspase, namely caspase- 9 , and can thus trigger the activation of the executioner caspase, namely caspase-3, eventually causing caspase-dependent apoptosis (44). AIF stimulates caspase-independent apoptosis by moving into 

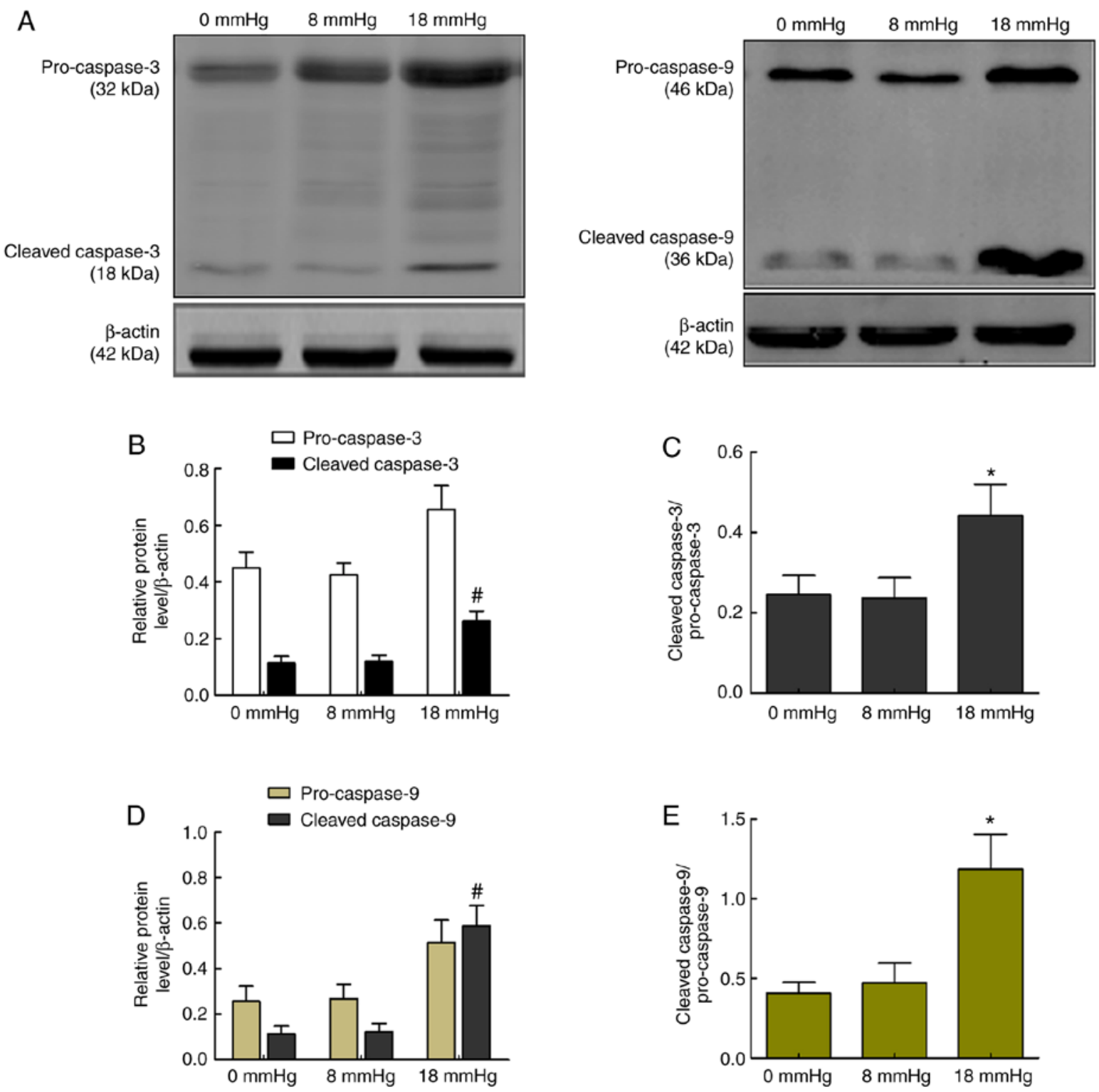

Figure 8. Expression levels of caspase-3 and caspase-9 in rabbit kidneys with severe hydronephrosis subjected to different pneumoperitoneum pressures. (A) Representative western blots demonstrating the protein expression levels of caspase-3, caspase- 9 and $\beta$-actin in rabbit kidneys from different groups. (B) Relative expression of pro-caspase-3 and cleaved-caspase-3 in each group compared with $\beta$-actin. (C) Ratio of cleaved-caspase-3/pro-caspase-3 expression in each group. (D) Relative expression of pro-caspase- 9 and cleaved-caspase-9 in each group compared with $\beta$-actin. (E) Ratio of cleaved-caspase-9/pro-caspase-9 expression in each group. All data are expressed as the mean \pm standard deviation, and each experiment was conducted in triplicate. $\mathrm{P}<0.05$ vs. cleaved-caspase in 0 and $8 \mathrm{mmHg}$ groups; " $\mathrm{P}<0.05$ vs. cleaved-caspase/pro-caspase levels in 0 and $8 \mathrm{mmHg}$ groups.

the nucleus, where it binds to DNA and stimulates chromatin condensation and DNA fragmentation (45). Additionally, the Bcl-2 family proteins, including anti-apoptotic (such as Bcl-2) and pro-apoptotic (such as Bax) members, serve an important role in the mitochondria-mediated pathway (46). The anti-apoptotic proteins inhibit the release of apoptosis-promoting factors, whereas the pro-apoptotic proteins promote the apoptotic process by regulating MMP and the permeability of membranes $(47,48)$. Accordingly, the present study investigated a number of important proteins associated with the mitochondria-mediated pathway. The western blot analysis results revealed significant downregulation of Bcl-2 and upregulation of Bax, as well as marked release of Cyt $\mathrm{c}$ from mitochondria into the cytosol, in the $18 \mathrm{mmHg}$ group. A significant increase in the expression of cleaved caspase-3 and cleaved caspase-9 was also observed in the $18 \mathrm{mmHg}$ group. Taken together, the current results provide evidence that apoptosis in rabbit kidneys with hydronephrosis induced by high $\mathrm{CO}_{2}$ pneumoperitoneum is associated with the mitochondria-dependent pathway. An illustration of how high-pressure $\mathrm{CO}_{2}$ pneumoperitoneum induces oxidative stress and mitochondria-dependent apoptosis in rabbit kidneys with severe hydronephrosis is shown in Fig. 9.

However, the present study has several important limitations. While the protocol following the method described by Wen et al (19) is an acceptable research model for kidney with hydronephrosis, it differs from hydronephrosis kidneys in humans. Therefore, how hydronephrosis affects the renal blood flow may differ between the species. Another issue to be stressed is the difference in the effects of pneumoperitoneum in 


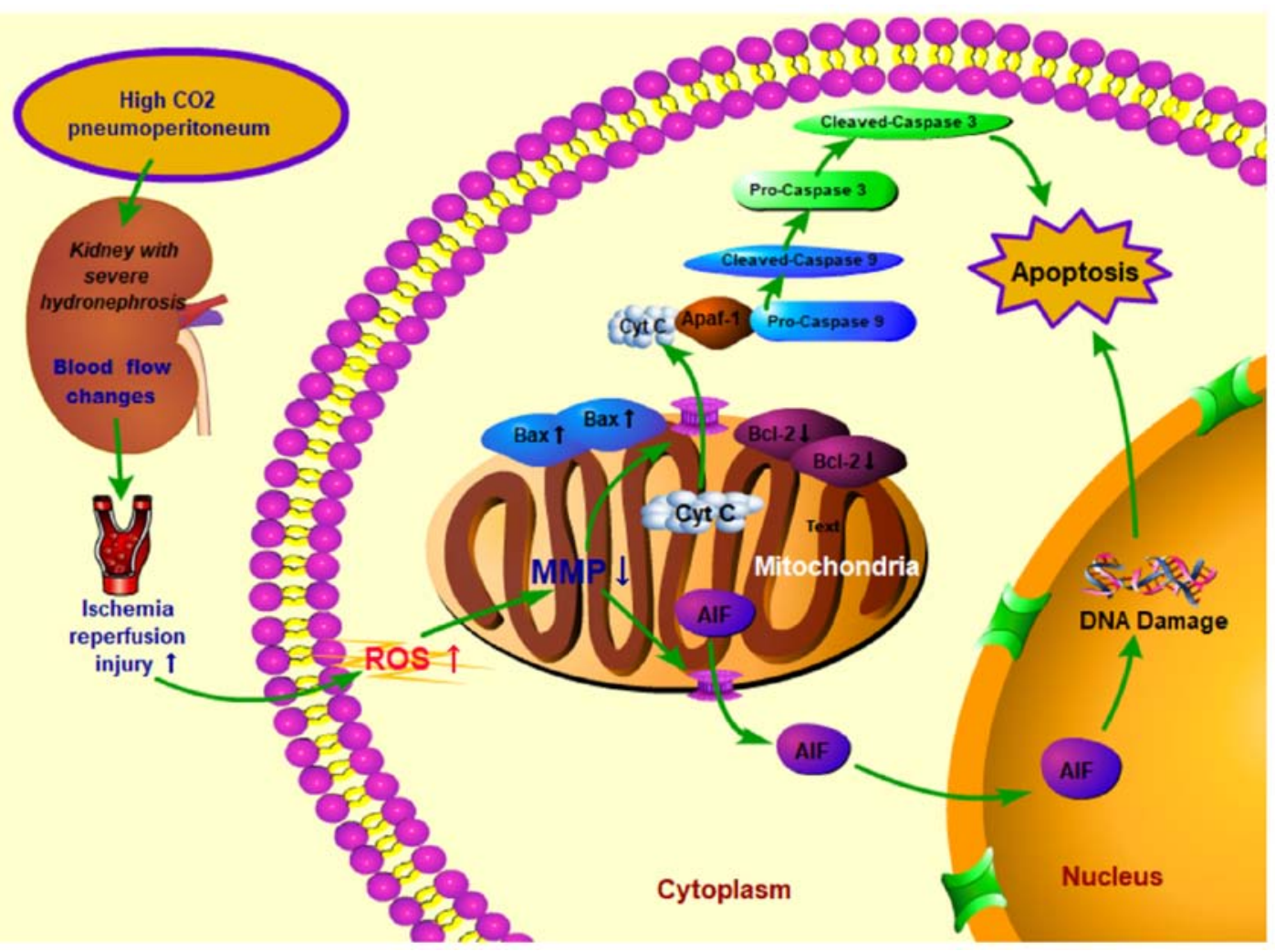

Figure 9. Proposed mechanisms of cell apoptosis induced by high $\mathrm{CO}_{2}$ pneumoperitoneum pressure in rabbit kidneys with severe hydronephrosis. High $\mathrm{CO}_{2}$ pneumoperitoneum pressure induced renal blood flow changes and increased the accumulation of ROS, resulting in upregulated Bax and downregulated Bcl-2 levels in kidneys. Consequently, the MMP was reduced, which then accelerated the release of Cyt $\mathrm{c}$ into the cytoplasm, leading to apoptosis via the caspase-3 and caspase-9-dependent pathway. $\mathrm{CO}_{2}$, carbon dioxide; MMP, mitochondrial membrane potential; ROS, reactive oxygen species; Bcl-2, B-cell lymphoma 2; Bax, Bcl-2-associated x protein; Cyt c, cytochrome C; AIF, apoptosis inducing factor.

the rabbit abdomen compared with that in the human abdomen for a given pressure, since the level of cell tolerance to intraabdominal pressure may differ between humans and rabbits (49). To the best of our knowledge, there has been no comparison between the kidney surface area in the two species; therefore, calculations of force per unit of surface area are not available. In humans, pneumoperitoneum pressure is recommended to be controlled to $<8 \mathrm{mmHg}$ (8). Considering the aforementioned important limitations, the experimental grouping was simplified, and three groups were set up with the pressures of 0 (no pressure), 8 (low pressure) and $18 \mathrm{mmHg}$ (high pressure). We believed that these three groups were sufficient for to investigate how high-pressure $\mathrm{CO}_{2}$ pneumoperitoneum affects kidneys with severe hydronephrosis. Furthermore, the insufflation with $\mathrm{CO}_{2}$ in the present study was performed at room temperature $\left(20-25^{\circ} \mathrm{C}\right)$ and dry conditions ( $0-5 \%$ relative humidity), and the intraabdominal pressure lasted for $90 \mathrm{~min}$. According to a previous meta-analysis, warming and humidifying the gas used for insufflation has been proposed to reduce the iatrogenic effects of laparoscopic surgery, including pain, hypothermia and peritoneal alterations (50). However, a prospective randomized trial confirmed that heating and humidification of $\mathrm{CO}_{2}$ during pneumoperitoneum is not indicated (51). Another experimental study also confirmed that the use of warming and humidification of insufflation gas had no effect on oxidative stress compared with the controls treated with unheated and non-humidified gas (52). Furthermore, the findings of Akbulut et al (53) indicated that the operating time should be limited to $<120 \mathrm{~min}$ during laparoscopic surgery, since the prolonged duration of pneumoperitoneal pressure may cause increased oxidative problems (54). The present study only explored how high-pressure $\mathrm{CO}_{2}$ pneumoperitoneum affects kidneys with severe hydronephrosis. However, the properties of the gas and the duration of intraabdominal pressure should also be studied. Notably, a number of other important molecules or apoptotic factors also exist that should be detected in order to clarify the mechanism of the mitochondria-dependent pathway of apoptosis.

Bcl-2 homology domain 3 (BH3)-only proteins, such as Bad, Bim, Bid, Puma and Noxa, are known to be important proteins that initiate and regulate cell apoptosis (55). These proteins are involved in apoptosis by translocating from the cytoplasm to mitochondria, and then inhibiting the activity of anti-apoptotic members (such as Bcl-2) or activating the activity of pro-apoptotic members (such as Bax/Bak) $(56,57)$. Other apoptosis pathways or certain other important molecules may also be associated with the activation of $\mathrm{BH} 3$-only proteins. For instance, the phosphorylation of Bad is associated with the PI3K-Akt pathway, while the cleavage of Bid is closely associated with the Fas death signaling pathway (58). P53, another important apoptotic member in DNA damage apoptosis, regulates the expression of Noxa and Puma (59). By contrast, a number of apoptotic molecules, such as Smac, AIF and Endo $\mathrm{G}$, are also important apoptotic members that are released from mitochondria subsequent to a decrease of MMP. These molecules play apoptotic roles by activating the caspase-3 pathway or by causing DNA damage $(60,61)$. In the present study, the 
expression levels of Bcl-2, Bax, Cyt c, caspase-3 and caspase-9 were detected, and the results indicated that the apoptosis in severe hydronephrosis kidneys induced by high-pressure $\mathrm{CO}_{2}$ pneumoperitoneum may be associated with the mitochondria-dependent apoptotic pathway. However, further studies regarding other aforementioned proteins or potential targets should be conducted to fully understand the exact mechanism underlying this type of apoptosis. The application of certain drugs to inhibit or promote mitochondria-dependent apoptosis in animals can also be investigated.

In conclusion, the results of the present study indicate that high-pressure $\mathrm{CO}_{2}$ pneumoperitoneum induces oxidative stress and causes apoptosis in rabbit kidneys with severe hydronephrosis through the mitochondrial apoptotic pathway. These conclusions were supported by the increased generation of ROS, loss of MMP, increased percentage of swollen or vacuolar mitochondria, Cyt c release, altered expression of Bcl-2 family proteins and activation of the caspase- $9 / 3$ cascade in the high pressure (18 $\mathrm{mmHg}$ ) group. Thus, these findings offer theoretical guidance for the application of pneumoperitoneum in laparoscopic surgery. These results also provide an insight into the molecular mechanism by which hydronephrosis protects the kidneys during laparoscopic surgery.

\section{Acknowledgements}

Not applicable.

\section{Funding}

The present study was supported by a grant from the Nation Natural Science Fund Project of China (no. 81400698).

\section{Availability of data and materials}

The datasets used and/or analyzed during the current study are available from the corresponding author on reasonable request.

\section{Authors' contributions}

SZ and WL performed the experiment and were major contributors in writing the manuscript. FC conceived and designed the experiments. JN supplied the materials and analyzed the data. TR, WY and YR collected and analyzed the data. XY and RY supplied the materials and analyzed the data. All authors read and approved the final manuscript.

\section{Ethics approval and consent to participate}

The present study was approved by the Ethical and Research Committee of Wuhan University Medical School (Wuhan, China).

\section{Patient consent for publication}

Not applicable.

\section{Competing interests}

The authors declare that they have no competing interests.

\section{References}

1. Siow SL, Mahendran HA, Wong CM, Hardin M and Luk TL: Laparoscopic versus open repair of perforated peptic ulcer: Improving outcomes utilizing a standardized technique. Asian J Surg 41: 136-142, 2016.

2. Seims AD, VanHouwelingen L, Mead J, Mao S, Loh A, Sandoval JA, Davidoff AM, Wu J and Wang WC: Operative and immediate postoperative differences between traditional multiport and reduced port laparoscopic total splenectomy in pediatric patients. J Laparoendosc Adv Surg Tech A 27: 206-210, 2017.

3. Jin B, Chen MT, Fei YT, Du SD and Mao YL: Safety and efficacy for laparoscopic versus open hepatectomy: A meta-analysis. Surg Oncol 27: A26-A34, 2017.

4. Menes T and Spivak H: Laparoscopy: Searching for the proper insufflation gas. Surg Endosc 14: 1050-1056, 2000.

5. Chen X, Liu H, Feng L and Liu Y: Effect of carbon dioxide pneumoperitoneal pressure on the ultrastructure of implanted endometriotic lesions in a rat model. Eur J Obstet Gynecol Reprod Biol 171: 319-324, 2013.

6. Hejazi M, Pedram MS, Ashegh H, Jafari N, Ghazisaeedi F and Abdi M: Evaluation of effects of intraperitoneal $\mathrm{CO}_{2}$ pressure in laparoscopic operations on kidney, pancreas, liver and spleen in dogs. Iran Red Crescent Med J 15: 809-812, 2013.

7. Liu Y, Cao W, Liu Y, Wang Y, Lang R, Yue Y and Wu AS: Changes in duration of action of rocuronium following decrease in hepatic blood flow during pneumoperitoneum for laparoscopic gynaecological surgery. Bmc Anesthesiol 17: 45, 2017.

8. Sassa N, Hattori R, Yamamoto T, Kato M, Komatsu T, Matsukawa Y, Funahashi Y and Gotoh M: Direct visualization of renal hemodynamics affected by carbon dioxide-induced pneumoperitoneum. Urology 73: 311-315, 2009.

9. Lee JY and Choi SH: Results of hepatic and renal function tests to different $\mathrm{CO} 2$ pneumoperitoneum conditions: An experimental capnoperitoneum study in dogs. Res Vet Sci 101: 1-5, 2015.

10. Akdemir A, Taylan E, Sahin C, Ozgurel B, Karlitepe A, Zekioglu $\mathrm{O}$ and Ercan G: The impact of carbon dioxide pneumoperitoneum on ovarian ischemia-reperfusion injury during iaparoscopic surgery: A preliminary study. J Minim Invasive Gynecol 25: 638-643, 2018.

11. Demyttenaere S, Feldman LS and Fried GM: Effect of pneumoperitoneum on renal perfusion and function: A systematic review. Surg Endosc 21: 152-160, 2007.

12. Ozmen MM, Zulfikaroglu B, Besler TH, Col C, Cinel L and Cinel I: The correlation between reactive oxygen species and histopathology of the liver, gut, and kidneys in animals with elevated intra-abdominal pressure. J Laparoendosc Adv Surg Tech A 19: 339-343, 2009.

13. Sammour T, Mittal A, Loveday BP, Kahokehr A, Phillips AR, Windsor JA and Hill AG: Systematic review of oxidative stress associated with pneumoperitoneum. Br J Surg 96: 836-850, 2009.

14. de Seigneux S, Klopfenstein CE, Iselin C and Martin PY: The risk of acute kidney injury following laparoscopic surgery in a chronic kidney disease patient. NDT Plus 4: 339-341, 2011.

15. Li W, Cao Z, Xia Z, Meng Q, Yu WM, Yao X and Cheng F: Acute kidney injury induced by various pneumoperitoneum pressures in a rabbit model of mild and severe hydronephrosis. Urol Int 94: 225-233, 2015.

16. Li W, Zhao S, Cheng F, Rao T, Yu W, Ruan Y, Yuan R and Yao X: Oxidative damage and mitochondrial injuries differ following pneumoperitoneum pressure in rabbit models of varying degrees of hydronephrosis. Mol Med Rep 17: 6819-6827, 2018.

17. Chen SD, Yang DI, Lin TK, Shaw FZ, Liou CW and Chuang YC: Roles of oxidative stress, apoptosis, PGC-1alpha and mitochondrial biogenesis in cerebral ischemia. Int J Mol Sci 12: 7199-7215, 2011.

18. National Research Council: Guide For The Care and Use of Laboratory Animals. National Acadamies Press, Washington, DC, 1996

19. Wen JG, Chen Y, F Frøkiaer J, Jørgensen TM and Djurhuus JC: Experimental partial unilateral ureter obstruction. I. Pressure flow relationship in a rat model with mild and severe acute ureter obstruction. J Urol 160: 1567-1571, 1998.

20. Ly JD, Grubb DR and Lawen A: The mitochondrial membrane potential (deltapsi(m)) in apoptosis; an update. Apoptosis 8: 115-128, 2003.

21. Perelman A, Wachtel C, Cohen M, Haupt S, Shapiro H and Tzur A: JC-1: Alternative excitation wavelengths facilitate mitochondrial membrane potential cytometry. Cell Death Dis 3: e430, 2012. 
22. Zhu X, Wang K, Zhang K, Huang B, Zhang J, Zhang Y, Zhu L, Zhou B and Zhou F: Ziyuglycoside II inhibits the growth of human breast carcinoma MDA-MB-435 cells via cell cycle arrest and induction of apoptosis through the mitochondria dependent pathway. Int J Mol Sci 14: 18041-18055, 2013.

23. Chen Q, Xu H, Xu A, Ross T, Bowler E, Hu Y and Lesnefsky EJ: Inhibition of Bcl-2 sensitizes mitochondrial permeability transition pore (MPTP) opening in ischemia-damaged mitochondria. PLoS One 10: e118834, 2015.

24. Eleftheriadis T, Pissas G, Liakopoulos V and Stefanidis I: Cytochrome $\mathrm{C}$ as a potentially clinical useful marker of mitochondrial and cellular damage. Front Immunol 7: 279, 2016.

25. Feinstein-Rotkopf $Y$ and Arama E: Can't live without them, can live with them: Roles of caspases during vital cellular processes. Apoptosis 14: 980-995, 2009.

26. Khoury W, Jakowlev K, Fein A, Orenstein H, Nakache R and Weinbroum AA: Renal apoptosis following carbon dioxide pneumoperitoneum in a rat model. J Urol 180: 1554-1558, 2008.

27. Wiesenthal JD, Fazio LM, Perks AE, Blew BD, Mazer D, Hare G Honey RJ and Pace KT: Effect of pneumoperitoneum on renal tissue oxygenation and blood flow in a rat model. Urology 77 : $1508-1509,2011$

28. Richards WO, Scovill W, Shin B and Reed W: Acute renal failure associated with increased intra-abdominal pressure. Ann Surg 197: 183-187, 1983.

29. Bishara B, Ramadan R, Karram T, Awad H, Abu-Saleh N, Winaver J, Assadi A and Abassi Z: Nitric oxide synthase inhibition aggravates the adverse renal effects of high but not low intraabdominal pressure. Surg Endosc 24: 826-833, 2010

30. Hashikura Y, Kawasaki S, Munakata Y, Hashimoto S, Hayashi K and Makuuchi M: Effects of peritoneal insufflation on hepatic and renal blood flow. Surg Endosc 8: 759-761, 1994.

31. Sodha S, Nazarian S, Adshead JM, Vasdev N and Mohan-S G: Effect of pneumoperitoneum on renal function and physiology in patients undergoing robotic renal surgery. Curr Urol 9: 1-4, 2016.

32. Nickkholgh A, Barro-Bejarano M, Liang R, Zorn M, Mehrabi A, Gebhard MM, Büchler MW, Gutt CN and Schemmer P: Signs of reperfusion injury following $\mathrm{CO} 2$ pneumoperitoneum: An in vivo microscopy study. Surg Endosc 22: 122-128, 2008.

33. Richter S, Olinger A, Hildebrandt U, Menger MD and Vollmar B Loss of physiologic hepatic blood flow ("hepatic arterial buffer response') during $\mathrm{CO} 2$-pneumoperitoneum in the rat. Anesth Analg 93: 872-877, 2001

34. Guven S, Muci E, Unsal MA, Yulug E, Alver A, Kadioglu Duman M and Mentese A: The effects of carbon dioxide pneumoperitoneum on ovarian blood flow, oxidative stress markers, and morphology during laparoscopy: A rabbit model. Fertil Steril 93: 1327-1332, 2010.

35. Oksuz H, Bulbuloglu E, Senoglu N, Ciralik H, Yuzbasioglu MF, Kilinc M, Dogan Z, Goksu M, Yildiz H, Ozkan OV and Atli Y: Re-protective effects of pre- and post-laparoscopy conditioning, zinc, pentoxifylline, and $\mathrm{N}$-acetylcysteine in an animal model of laparoscopy-induced ischemia/reperfusion injury of the kidney. Ren Fail 31: 297-302, 2009.

36. Gao Y, Chen T, Lei X, Li Y, Dai X, Cao Y, Ding Q, Lei X, Li T and Lin X: Neuroprotective effects of polydatin against mitochondrial-dependent apoptosis in the rat cerebral cortex following ischemia/reperfusion injury. Mol Med Rep 14: 5481-5488, 2016.

37. Chevalier RL, Thornhill BA, Forbes MS and Kiley SC: Mechanisms of renal injury and progression of renal disease in congenital obstructive nephropathy. Pediatr Nephrol 25: 687-697, 2010 .

38. Shigeta K, Kikuchi E, Hagiwara M, Hattori S, Kaneko G, Hasegawa M, Takeda T, Jinzaki M, Akita H, Miyajima A, et al: Visceral to total obesity ratio and severe hydronephrosis are independently associated with prolonged pneumoperitoneum operative time in patients undergoing laparoscopic radical nephroureterectomy for upper tract urothelial carcinoma. Springerplus 4: 290, 2015.

39. Bauer V and Bauer F: Reactive oxygen species as mediators of tissue protection and injury. Gen Physiol Biophys Spec No: 7-14, 1999.

40. Maslov LN, Naryzhnaia NV, Podoksenov I, Prokudina ES, Gorbunov AS, Zhang I and Pei Z: Reactive oxygen species are triggers and mediators of an increase in cardiac tolerance to impact of ischemia-reperfusion. Ross Fiziol Zh Im I M Sechenova 101: 3-24, 2015 (In Russian).
41. Tajeddine N: How do reactive oxygen species and calcium trigger mitochondrial membrane permeabilisation? Biochim Biophys Acta 1860: 1079-1088, 2016.

42. Murphy MP: How mitochondria produce reactive oxygen species. Biochem J 417: 1-13, 2009.

43. Zhang M, Zheng J, Nussinov R and Ma B: Release of cytochrome $\mathrm{C}$ from bax pores at the mitochondrial membrane. Sci Rep 7: 2635, 2017.

44. Huttemann M, Pecina P, Rainbolt M, Sanderson TH, Kagan VE, Samavati L, Doan JW and Lee I: The multiple functions of cytochrome $\mathrm{c}$ and their regulation in life and death decisions of the mammalian cell: From respiration to apoptosis. Mitochondrion 11: 369-381, 2011

45. Boujrad H, Gubkina O, Robert N, Krantic S and Susin SA: AIF-mediated programmed necrosis: A highly regulated way to die. Cell Cycle 6: 2612-2619, 2007.

46. Basanez G, Soane L and Hardwick JM: A new view of the lethal apoptotic pore. PLoS Biol 10: e1001399, 2012.

47. Kushnareva Y, Andreyev AY, Kuwana T and Newmeyer DD: Bax activation initiates the assembly of a multimeric catalyst that facilitates Bax pore formation in mitochondrial outer membranes. PLoS Biol 10: e1001394, 2012.

48. Chipuk JE and Green DR: How do BCL-2 proteins induce mitochondrial outer membrane permeabilization? Trends Cell Biol 18: 157-164, 2008.

49. Avital S, Itah R, Szomstein S, Rosenthal R, Inbar R, Sckornik Y and Weinbroum A: Correlation of $\mathrm{CO}_{2}$ pneumoperitoneal pressures between rodents and humans. Surg Endosc 23: 50-54, 2009

50. Balayssac D, Pereira B, Bazin JE, Le Roy B, Pezet D and Gagniere J: Warmed and humidified carbon dioxide for abdominal laparoscopic surgery: Meta-analysis of the current literature. Surg Endosc 31: 1-12, 2017.

51. Davis SS, Mikami DJ, Newlin M, Needleman BJ, Barrett MS, Fries R, Larson T, Dundon J, Goldblatt MI and Melvin WS: Heating and humidifying of carbon dioxide during pneumoperitoneum is not indicated: A prospective randomized trial. Surg Endosc 20: 153-158, 2006.

52. Sammour T, Mittal A, Delahunt B, Phillips AR and Hill AG: Warming and humidifcation have no effect on oxidative stress during pneumoperitoneum in rats. Minim Invasive Ther Allied Technol 20: 329-337, 2011.

53. Akbulut G, Polat C, Aktepe F, Yilmaz S, Kahraman A, Serteser M, Gökçe C and Gökçe O: The oxidative effect of prolonged $\mathrm{CO} 2$ pneumoperitoneum on renal tissue of rats. Surg Endosc 18: 1384-1388, 2004

54. Hoekstra LT, Ruys AT, Milstein DM, van Samkar G, van Berge HM, Heger M, Verheij J and van Gulik TM: Effects of prolonged pneumoperitoneum on hepatic perfusion during laparoscopy. Ann Surg 257: 302-307, 2013.

55. Doerflinger M, Glab JA and Puthalakath $\mathrm{H}$ : $\mathrm{BH} 3$-only proteins: A 20-year stock-take. FEBS J 282: 1006-1016, 2015.

56. Gerecova $G$, Kopanicova J, Jaka $P$, Běhalová L, Juhásová $B$, Bhatia-Kiššová I, Forte M, Polčic P and Mentel M: BH3-only proteins Noxa, Bik, Bmf, and Bid activate Bax and Bak indirectly when studied in yeast model. Fems Yeast Res 13: 747-754, 2013.

57. Juhasova B, Mentel M, Bhatia-Kissova I, Zeman I, Kolarov J, Forte $\mathrm{M}$ and Polčic P: BH3-only protein Bim inhibits activity of antiapoptotic members of Bcl-2 family when expressed in yeast. FEBS Lett 585: 2709-2713, 2011.

58. Tegla CA, Cudrici C, Patel S, Trippe R, Rus V, Niculescu F and Rus H: Membrane attack by complement: The assembly and biology of terminal complement complexes. Immunol Res 51: 45-60, 2011.

59. Schuler M and Green DR: Mechanisms of p53-dependent apoptosis. Biochem Soc Trans 29: 684-688, 2001

60. Zhang J, Ye J, Altafaj A, Cardona M, Bahi N, Llovera M, Cañas X, Cook SA, Comella JX and Sanchis D: EndoG links Bnip3-induced mitochondrial damage and caspase-independent DNA fragmentation in ischemic cardiomyocytes. PLoS One 6: e17998, 2011.

61. Kilbride SM and Prehn JH: Central roles of apoptotic proteins in mitochondrial function. Oncogene 32: 2703-2711, 2013.

This work is licensed under a Creative Commons Attribution-NonCommercial-NoDerivatives 4.0 International (CC BY-NC-ND 4.0) License. 